\title{
Non-Isothermal Degradation and Kinetics Studies of Some Quinaldine Azo Dye Complexes
}

\author{
L. M. Al-Harbi ${ }^{1}$, E. H. El-Mossalamy ${ }^{1,2}$, I. S. Ahmed ${ }^{2}$, A. Y. Obaid ${ }^{1}$ \\ ${ }^{1}$ Chemisty Department, Faculty of Science, King Abdulaziz University, Jeddah, Saudi Arabia \\ ${ }^{2}$ Chemistry Department, Faculty of Science, Benha University, Benha City, Egypt \\ Email: 1majeed2002@yahoo.com
}

Received June 24, 2013; revised July 25, 2013; accepted August 10, 2013

Copyright (C) 2013 L. M. Al-Harbi et al. This is an open access article distributed under the Creative Commons Attribution License, which permits unrestricted use, distribution, and reproduction in any medium, provided the original work is properly cited.

\begin{abstract}
4-(R-Phenylazo)-2-methyl quinoline derivatives form (1:1) complexes with nickel chloride, nickel acetate and copper acetate which were syntheses. The three complexes are non-electrolyte in dimethylsulfoxide (DMF). The results of electronic and magnetic measurements show that these complexes are of octahedral structures. The oxygen and nitrogen donate their lone-pair electrons to metal ion to form chelates with formula $\left[\mathrm{MLR}_{\mathrm{m}} \cdot \mathrm{nH}_{2} \mathrm{O}\right]$. The relative stabilities of the complexes have been calculated from TG curve using Coats-Redfern and Ozawa methods.
\end{abstract}

Keywords: Non-Isothermal; Kinetic Parameters; Azo Dye Derivatives; Magnetic Measurements; Spectra Studies

\section{Introduction}

Azo compounds have been the subject of numerous spectral studies aimed at their identification or structural elucidation [1-4]. Interest in azo compounds stems from their ability to form metal chelates with metal ions $[5,6]$. The synthesis and characterization of new metal chelate derived from the kinaldine azo dye have been reported [7], but no report concerning the solid-state kinetics of such complexes has been published.

The aims of the present investigation are the preparation and elucidation of the geometrical structure of the metal chelates formed between divalent transition metal ions with different counter ions of acetate or chloride. The kinetics of the thermal decomposition of the azo dye complexes was also studied using dynamic thermogravimetric techniques.

\section{Experimental}

\subsection{Material}

All chemicals were used of pure grade (BDH or Aldrich). The preparation of the kinaldline azo dye followed the procedure described in the literature [7]. The chemical structure of this compound is shown in Figure 1.

\subsection{Synthesis of Metal Chelates}

The metal chelates were prepared by mixing equal vol- umes $(40 \mathrm{ml})$ of hot ethanolic solutions of kinaladine azo dye and the metal salts $(0.02 \mathrm{~mol}) \mathrm{Cu}(\mathrm{OAc})_{2} \cdot \mathrm{H}_{2} \mathrm{O}$, $\left(\mathrm{Ni}(\mathrm{OAc}) \cdot 2 \mathrm{H}_{2} \mathrm{O}\right.$ or $\left(\mathrm{NiCl}_{2} \cdot 6 \mathrm{H}_{2} \mathrm{O}\right)$. The mixture left for 3 hours in steam bath, to adjust the $\mathrm{pH}$ to $6-8$ by adding few drops of ammonia solution with continuous starring. The precipitate is washed with mixture of distilled water and ethanol until the filtrate becomes colorless; the chelates were collected and dried.

\section{Results and Discussion}

The stoichiometric ratio is (1:1) between the metal and ligand, the formulas of the three complexes under investtigation are $\left[\mathrm{M} \mathrm{LR} \mathrm{mX} \cdot \mathrm{nH}_{2} \mathrm{O}\right] \cdot \mathrm{yH}_{2} \mathrm{O}$, where $\mathrm{M}=\mathrm{Ni}$ or $\mathrm{Cu}, \mathrm{X}=\mathrm{OAc}$ or $\mathrm{Cl}, \mathrm{m}=1, \mathrm{n}=3, \mathrm{y}=1$, and LR represents 4-(R-phenylazo)-2-methyl quinoline derivatives, $\mathrm{R}$ $=\mathrm{P}-\mathrm{NH}_{2}\left(\mathrm{~L}_{1}\right)$ or $\mathrm{R}=\mathrm{p}-\mathrm{COOH}\left(\mathrm{L}_{2}\right)$ respectively. The calculated values of the suggested structural formula of the chelates are in good agreement with the values obtained from elemental analysis data (Table 1) dimethylsulfoxide was used as solvent at $25^{\circ} \mathrm{C}$ to calculate the molar conductivities of the chelates which was found to be $13.25-20.2017 \mathrm{Ohm}^{-1}$, these value are in non-electrolytic region which mean these chelates are of nonelectrolytic nature $[8,9]$.

The water of hydration or coordination appear in the IR spectra of all metal chelates causes difficulty in drawing conclusions from the $v(\mathrm{OH})$ band for the hydroxyl groups of the free ligand, which would overlap 
those of water molecules. The participation of the hydroxyl group in the chelation is confirmed by the appearance of new band at $420-540 \mathrm{~cm}^{-1}$, which is related to $v \mathrm{M}-\mathrm{O}$ vibrations [10]. The band at $370-400 \mathrm{~cm}^{-1}$ corresponds to $v(\mathrm{M}-\mathrm{N})$ vibrations, [11] whereas the band at $340-350 \mathrm{~cm}^{-1}$ is attributed to $v(\mathrm{M}-\mathrm{Cl})$ vibrations [12]. The bands at $1580-1420 \mathrm{~cm}^{-1}$ correspond to the $v(\mathrm{C}=\mathrm{O})$ and $v(\mathrm{C}-\mathrm{O})$ vibrations of $\mathrm{CH}_{3} \mathrm{COO}^{-}$[13], respectively.

\section{Thermogravimetric Analysis}

D Thermal analysis were performed on chelates of $\left[\mathrm{CuL}_{1}\left(\mathrm{OOCCH}_{3}\right)\left(\mathrm{H}_{2} \mathrm{O}\right)_{3}\right] \cdot \mathrm{H}_{2} \mathrm{O}(\mathrm{I}) ;\left[\mathrm{NiL}_{1} \mathrm{Cl}\left(\mathrm{H}_{2} \mathrm{O}\right)_{3}\right] \cdot \mathrm{H}_{2} \mathrm{O}$ (II); and $\left.\mathrm{NiL}_{2}\left(\mathrm{OOCCH}_{3}\right)\left(\mathrm{H}_{2} \mathrm{O}\right)_{3}\right] \cdot \mathrm{H}_{2} \mathrm{O}$ (III). From TG curves weight loss at $120^{\circ} \mathrm{C}$ is assigned to the loss of hydrate water. The coordinate water in the metal chelates is lost in the second step in the range $120^{\circ} \mathrm{C}-220^{\circ} \mathrm{C}$. For the complexes (I-III), the weight losses are approximately $3.15 \%, 4.03 \%$ and $3.57 \%$, respectively, for the loss of a single water of hydration from the complexes. The weight losses of $11.96 \%, 12.17 \%$ and $10.74 \%$ for complexes (I-III), respectively, represent the removal of three coordinatively bounded water molecules from each of the complexes (I-III). From the TG curves in Figures 2 to 4 , the remaining weight losses were $8.4 \%, 13.9 \%$ and $8.5 \%$ at a heating rate $\beta=15^{\circ} \mathrm{C} / \mathrm{min} ; 13.9 \%, 15.5 \%$ and $11.0 \%$ at a heating rate $\beta=20^{\circ} \mathrm{C} / \mathrm{min}$; and $16.5 \%$, $17.5 \%$ and $13.5 \%$ at a heating rate $\beta=25^{\circ} \mathrm{C} / \mathrm{min}$ for complexes (I-III), respectively. These weight percentages are in good agreement with the values given in Table 1, for the complexes with the formulas suggested in Figure 5.

The TG results provide evidence for the formation of two types of oxides, depending on the heating rate. At aslow heating rate, the non-stoichiometric oxide of formula $\mathrm{M}_{1-\mathrm{x}} \mathrm{O}_{\mathrm{x}}(0.1 \leq \mathrm{x} \leq 0.5)$ formed, whereas the ideal oxide of suggested formula $\mathrm{MO}$ formed at the higher heating rate of $25^{\circ} \mathrm{C} / \mathrm{min}$ for all of the complexes.

The kinetics parameters, including the order of the decomposition (n), the activation energies $(\mathrm{Ea})$, the frequency factors $(Z)$ and the activation entropy $(\Delta S \#)$, were calculated from the TG curves for runs performed in air in the temperature range of $200^{\circ} \mathrm{C}-600^{\circ} \mathrm{C}$ using the Ozawa [14] and the Coats-Redfern methods [15]. The values of $\mathrm{n}, \mathrm{Ea}, \mathrm{Z}$ and $\Delta \mathrm{S} \#$ are given in Table 2 . The mechanism involved in the decomposition is that of ran dom nucleation. The complexation of the quinolineazo dye derivatives with the transition-metal ions $\mathrm{Ni}$ (II) and $\mathrm{Cu}(\mathrm{II})$ in the presence of different counter-ions requires different amounts of energy, which may be due to the differences in the electronic configurations of the transition metals or to the existence of water molecules in the

Table 1. Elemental analysis, thermogravimetric analysis and molar conductance results for metals chelated with 4-(R-phenylazo)-2-methylquinoline derivatives.

\begin{tabular}{|c|c|c|c|c|c|c|c|c|}
\hline & & $\% \mathrm{C}$ & $\% \mathrm{H}$ & $\% \mathbf{N}$ & $\% \mathbf{M}$ & $\% \mathrm{H}_{2} \mathrm{O}$ & $\% \mathrm{Cl}$ & \multirow{2}{*}{$\begin{array}{c}\Lambda_{\mathrm{m}} \text { molar conductance } \\
\mathbf{o h m}^{-1} \cdot \mathbf{c m}^{2} \cdot \mathbf{m o l}^{-1}\end{array}$} \\
\hline Compd. & Formula & $\begin{array}{l}\text { Calc. } \\
\text { (found) }\end{array}$ & $\begin{array}{l}\text { Calc. } \\
\text { (found) }\end{array}$ & $\begin{array}{l}\text { Calc. } \\
\text { (found) }\end{array}$ & $\begin{array}{l}\text { Calc. } \\
\text { (found) }\end{array}$ & $\begin{array}{c}\text { Calc. } \\
\text { (found) }\end{array}$ & $\begin{array}{c}\text { Calc. } \\
\text { (found) }\end{array}$ & \\
\hline $\mathbf{I}$ & {$\left[\mathrm{CuL}_{1}\left(\mathrm{OOCCH}_{3}\right)\left(\mathrm{H}_{2} \mathrm{O}\right)_{3}\right] \mathrm{H}_{2} \mathrm{O}$} & $\begin{array}{c}45.81 \\
(45.75)\end{array}$ & $\begin{array}{c}3.39 \\
(3.34)\end{array}$ & $\begin{array}{c}11.88 \\
(11.70)\end{array}$ & $\begin{array}{c}13.45 \\
(13.39)\end{array}$ & $\begin{array}{c}15.27 \\
(15.11)\end{array}$ & - & 20.17 \\
\hline II & {$\left[\mathrm{NiL}_{1} \mathrm{Cl} .\left(\mathrm{H}_{2} \mathrm{O}\right)_{3}\right] \mathrm{H}_{2} \mathrm{O}$} & $\begin{array}{c}43.32 \\
(43.15)\end{array}$ & $\begin{array}{c}2.93 \\
(2.84)\end{array}$ & $\begin{array}{c}12.63 \\
(12.50)\end{array}$ & $\begin{array}{c}13.24 \\
(13.18)\end{array}$ & $\begin{array}{c}16.25 \\
(16.20)\end{array}$ & $\begin{array}{c}8.01 \\
(7.75)\end{array}$ & 13.25 \\
\hline III & {$\left[\mathrm{NiL}_{2}\left(\mathrm{OOCCH}_{3}\right)\left(\mathrm{H}_{2} \mathrm{O}\right)_{3}\right] \mathrm{H}_{2} \mathrm{O}$} & $\begin{array}{c}46.00 \\
(45.540\end{array}$ & $\begin{array}{l}3.03 \\
(2.99)\end{array}$ & $\begin{array}{c}8.47 \\
(8.22)\end{array}$ & $\begin{array}{c}11.84 \\
(11.76)\end{array}$ & $\begin{array}{c}14.52 \\
(14.30)\end{array}$ & - & 19.34 \\
\hline
\end{tabular}

Table 2. Thermal kinetics parameters and results of magnetic measurements of metals chelated with 4-(R-phenylazo) 2-methylquinoline derivatives.

\begin{tabular}{|c|c|c|c|c|c|c|c|}
\hline Compd. & Order of reaction (n) & Equation due to & $\begin{array}{c}\text { Temperature range of } \\
\text { decomp. }\left({ }^{\circ} \mathrm{C}\right)\end{array}$ & $\begin{array}{c}\mathbf{E}_{\mathrm{a}} \\
\mathrm{kJ} \cdot \mathrm{mol}^{-1}\end{array}$ & $\begin{array}{c}\mathrm{Z} \\
\mathrm{S}^{-1}\end{array}$ & $\begin{array}{c}-\Delta \mathbf{S}^{\#} \\
\mathbf{k J K}^{-1} \cdot \mathbf{m o l}^{-1}\end{array}$ & $\begin{array}{c}\mu_{\text {eff }} \\
\text { B.M }\end{array}$ \\
\hline \multirow{3}{*}{$\mathbf{I}$} & \multirow{3}{*}{0.76} & Coats-Redfern & \multirow{3}{*}{$220-350$} & 111.70 & 31.50 & 96.34 & \multirow{3}{*}{1.82} \\
\hline & & & & & & & \\
\hline & & Ozawa & & 96.03 & 12.80 & 99.59 & \\
\hline \multirow{3}{*}{ II } & \multirow{3}{*}{0.83} & Coats-Redfern & \multirow{3}{*}{$190-320$} & 123.08 & 20.80 & 97.64 & \multirow{3}{*}{3.22} \\
\hline & & & & & & & \\
\hline & & Ozawa & & 110.50 & 30.40 & 96.30 & \\
\hline \multirow{3}{*}{ III } & \multirow{3}{*}{0.68} & Coats-Redfern & \multirow{3}{*}{$210-380$} & 114.88 & 39.8 & 95.70 & \multirow{3}{*}{3.15} \\
\hline & & & & & & & \\
\hline & & Ozawa & & 98.70 & 18.60 & 98.50 & \\
\hline
\end{tabular}




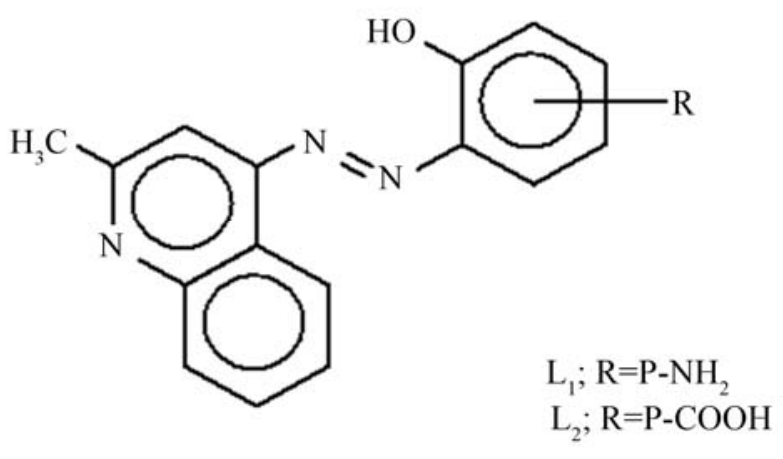

Figure 1. The chemical structure of kinaldine azo dye.

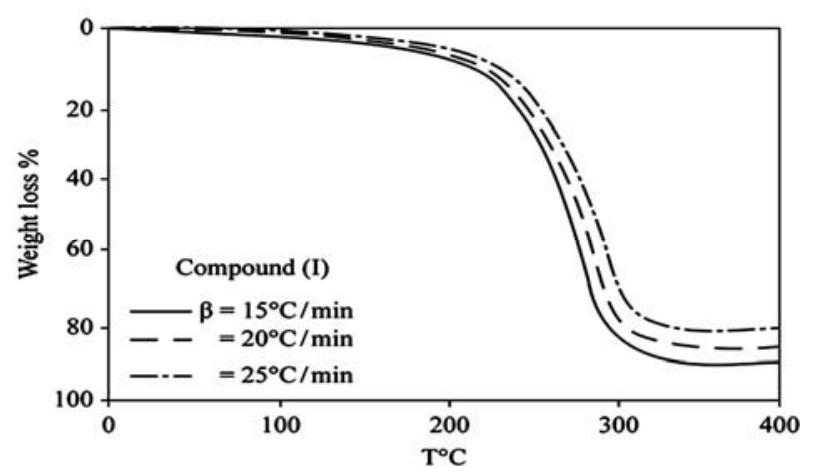

(a)

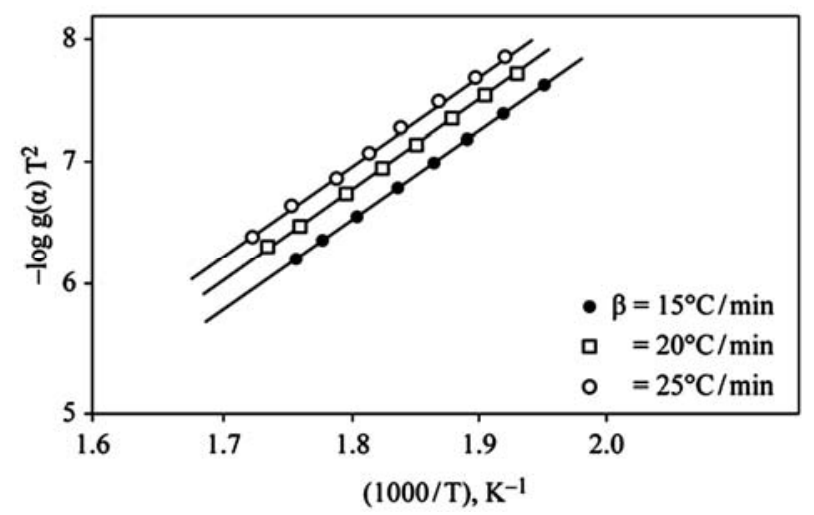

(b)

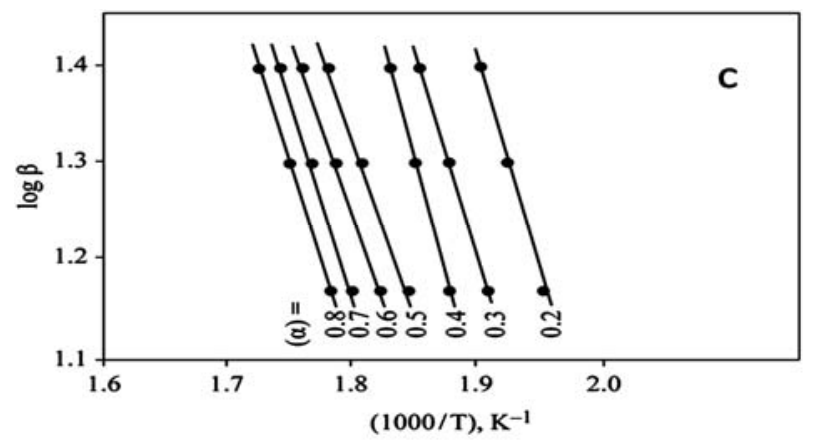

(c)

Figure 2. (a) TG curves of 4-(R-phenylazo)-2-methylquinoline complexes (I); (b) Cats-Redfern method of analysis; (c) Ozawa method of analysis.

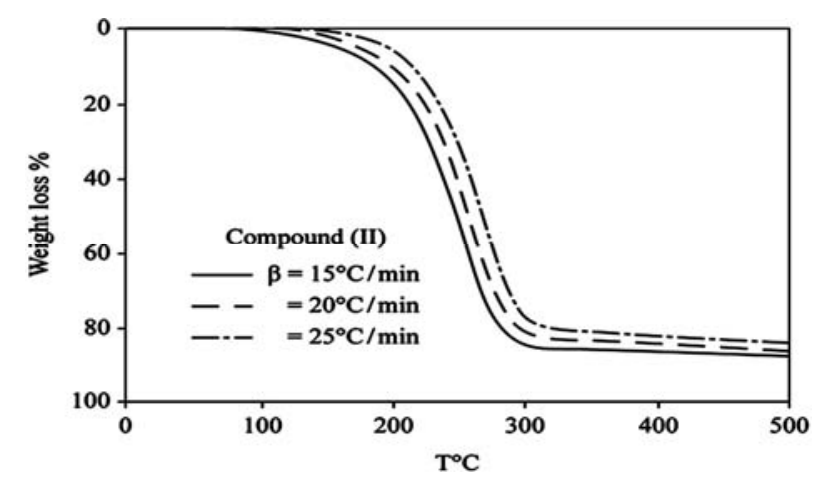

(a)

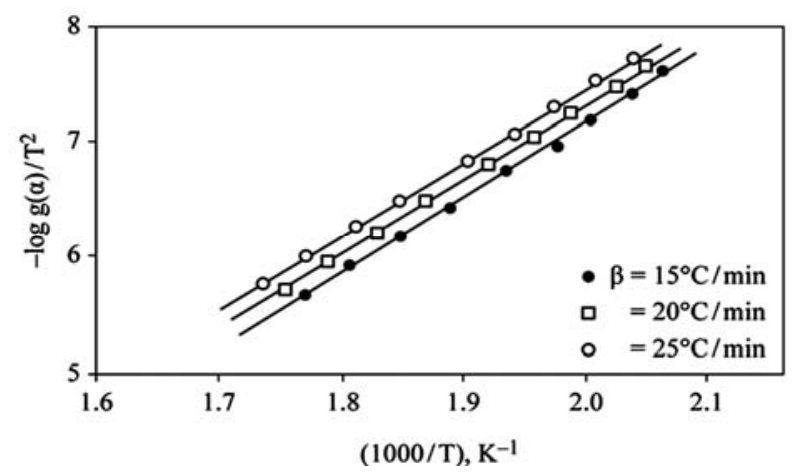

(b)

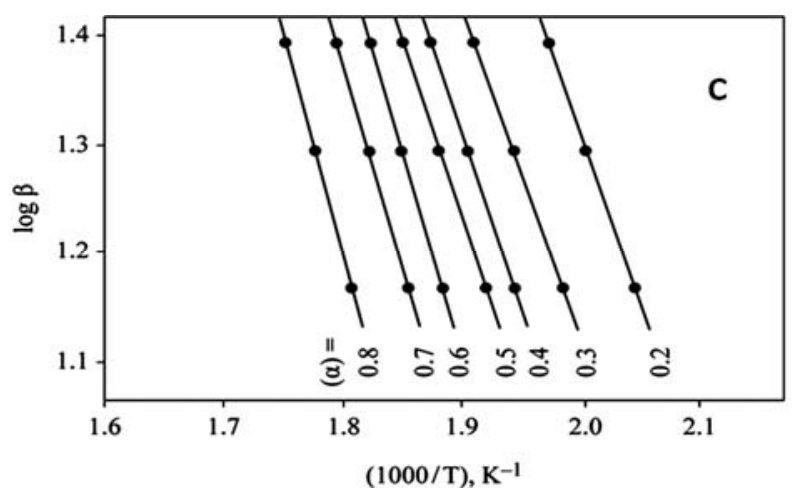

(c)

Figure 3. (a) TG curves of 4-(R-phenylazo)-2-methylquinoline complexes (II); (b) Cats-Redfern Method of analysis; (c) Ozawa method of analysis.

outer sphere, in addition to differences in several experimental factors. These factors may also influence the activation-energy values (Ea) that pertain to the thermal stability of the azo dye quinoline derivatives with $\mathrm{Cu}(\mathrm{II})$ and $\mathrm{Ni}(\mathrm{II})$ in the presence of different anions; these stabilities are arranged in the order II $>$ III $>$ I.

\section{Conclusions}

The $\mathrm{Ni}(\mathrm{II})$ and $\mathrm{Cu}$ (II) chelates of quinoline azo dye derivatived in the presence of different counter ions indicate octahedral arrangements which were obtained from the electronic spectral data and the magnetic moment values. 


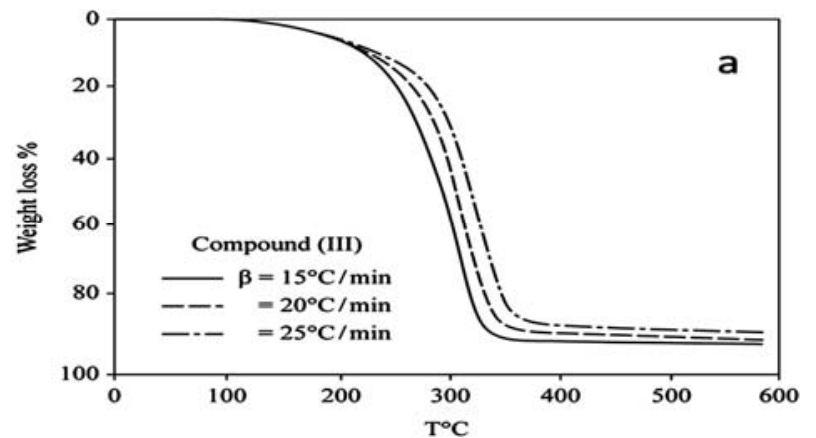

(a)

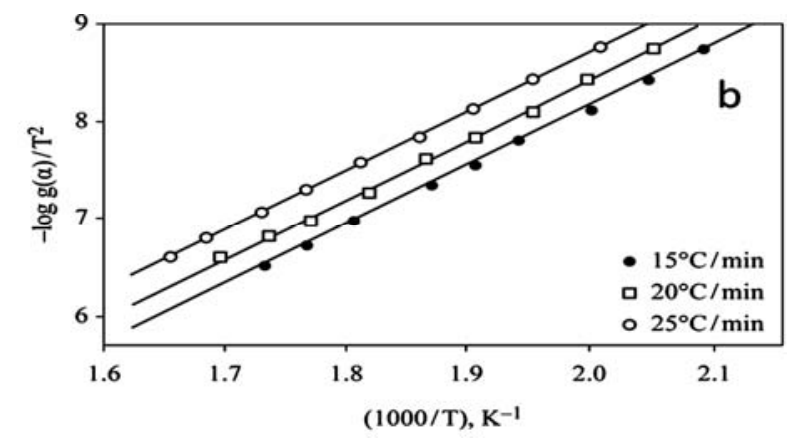

(b)

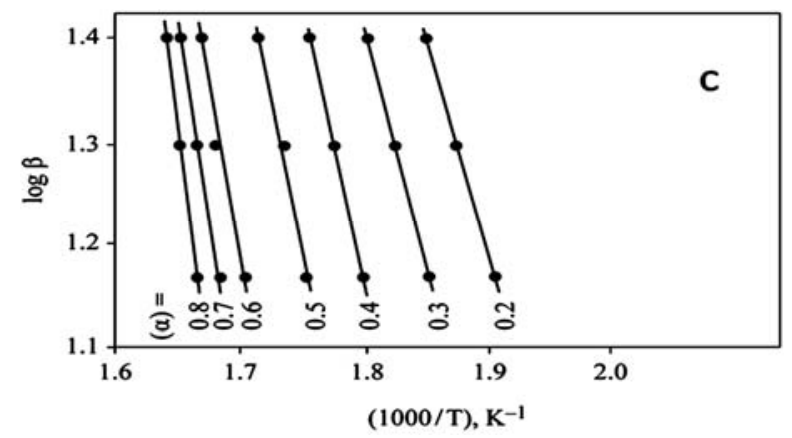

(c)

Figure 4. (a) TG curves o4-(R-phenylazo)-2-methylquinoline complexes (III); (b) Cats-Redfern method of analysis; (c) Ozawa method of analysis.

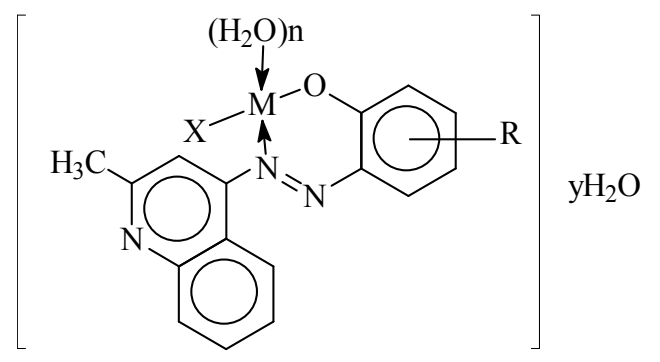

$$
\begin{aligned}
& \mathrm{R} ; \mathrm{P}-\mathrm{NH}_{2} \text { or } \mathrm{P}-\mathrm{COOH} \\
& \mathrm{X} ; \mathrm{Cl}^{-} \text {or } \mathrm{CH}_{3} \mathrm{COO}^{-} \\
& \mathrm{n}=3, \quad \mathrm{y}=1 \\
& \mathrm{M} ; \mathrm{Cu}(\mathrm{II}) \text { or } \mathrm{Ni} \text { (II) }
\end{aligned}
$$

Figure 5. Suggested structural formulas of the $\mathrm{Cu}$ (II) and $\mathrm{Ni}(\mathrm{II})$ chelates.
The structures of the chelates have been determined and show that the monobasic bidentate ligand is coordinated to the metal ions through the $\mathrm{OH}$ and $\mathrm{N}$ as donor atoms in $(1: 1)(\mathrm{M}: \mathrm{L})$ chelates. The kinetics parameters were calculated, and the higher values of Ea suggest a greater stability of the complexes. Furthermore, the negative values for the entropy of activation indicate that the activated complexes exhibit more ordered or more rigid structures.

\section{REFERENCES}

[1] I. A. Vogel, "Textbook of Practical Organic Chemistry Including Qualitative Organic Analysis," 3rd Edition, Longman, London, 1975.

[2] M. S. Masoud, A. A. Hasanein, A. M. Heiba, "Spectral Studies on Some Azo Compounds," Spectroscopy Letters, Vol. 17, No. 8, 1984, pp. 441-453. doi: $10.1080 / 00387018408062702$

[3] A. S. Shalabi, H. A. Dessouki, Y. M. Issa and I. S. Ahmed, "Spectral Studies and Molecular Orbital PPP-Calculations of Some Azo-Dyes," Spectrochemica Acta Part $A$, Vol. 58, No. 12, 2002, pp. 2765-2769. doi:10.1016/S1386-1425(02)00023-9

[4] R. Zhaoa, et al, "One Step Synthesis of Azo Compounds from Nitroaromatics and Anilines," Tetrahedron Letters, Vol. 52, No. 29, 2011, pp. 3805-3809

[5] E. H. El-Mossalamy, "Potentiometric and Spectroscopic Studies of Sulfonamide Azo-Dye Complexes with some Transition Metal Ions and Uranium," Portugaliae Electrochimica Acta, Vol. 27, No. 2, 2009.

[6] S. Wang, S. Shen, H. Xu, D. Gu, J. Yin and X. Tang, "Spectroscopic and Optical Properties of an Azo-Metal Chelate Dye as Optical Recording Medium," Materials Science and Engineering: B, Vol. 76, No. 1, 2000, pp. 69-72.

[7] E. H. Elmossalamy and A. S. Amin, "Spectrophotometric Studies of 4-(2-Hydroxy-4-substituted-azobenzene)-2 methyl-quinolines as Reagents for the Determination of Silver," Monatshefte für Chemie, Vol. 128, No. 1 1997, pp. 23-28.

[8] A. M. Shallaby, M. M. Mostafa and M. M. Bekheit, "Complexes of $\mathrm{Cu}(\mathrm{II}), \mathrm{Co}(\mathrm{II}), \mathrm{Ni}(\mathrm{II}), \mathrm{Cd}(\mathrm{II})$, and $\mathrm{Hg}(\mathrm{II})$ Halides with Hydrazones Derived from GIRARD T and Chromone," Journal of Inorganic and Nuclear Chemistry, Vol. 41, No. 2, 1978, pp. 267-269. doi:10.1016/0022-1902(79)80533-3

[9] W. J. Geary, "The Use of Conductivity Measurements in Organic Solvents for the Characterization of Coordination Compounds," Coordination Chemistry Reviews, Vol. 7, No. 1, 1971, pp. 81-122. doi:10.1016/S0010-8545(00)80009-0

[10] J. R. Ferraro, "Low Frequency Vibration of Inorganic and Coordination Compounds," Plenum Press, New York 1971.

[11] J. R. Ferraro and W. R. Walker, "Infrared Spectra of Hydroxy-Bridged Copper(II) Compounds," Inorganic Che- 
mistry, Vol. 4, No. 10, 1985, pp. 1382-1386. doi:10.1021/ic50032a002

[12] J. A. Faniran, K. S. Patel and L. O. Nelson, "Physico-Chemical Studies of Metal $\beta$-Diketonates-I Infrared Spectra of 1-(3-pyridyl)-1,3-butanedione and Its Divalent Metal Complexes," Journal of Inorganic and Nuclear Chemistry, Vol. 38, No. 1, 1976, p. 77. doi:10.1016/0022-1902(76)80053-X

[13] L. J. Bellamy, "The Infrared Spectra of Complex Molecules, Chapman and Hall, London, 1975. doi:10.1007/978-94-011-6017-9

[14] T. Ozawa, "A New Method of Analyzing Thermogravimetric Data," Chemical Society of Japan, Vol. 38, No. 11, 1965, pp. 1881-1887. doi:10.1246/bcsj.38.1881

[15] A. V. Coats and J. P. Redfern, "Kinetic Parameters from Thermogravimetric Data," Nature, Vol. 201, No. 4914, 1964, pp. 68-69. doi:10.1038/201068a0 